\title{
THE EFFECT OF KHELLIN ON CARDIO-PULMONARY FUNCTION IN CHRONIC PULMONARY DISEASE 1, 2
}

\author{
By E. N. SILBER, ${ }^{3}$ G. L. SNIDER, H. GOLDBERG, L. N. KATZ, AND D. B. RADNER \\ (From the Cardiovascular Department, Medical Research Institute, and the Chest Department, \\ Michael Reese Hospital, Chicago, Ill.) 4
}

(Submitted for publication February 26, 1951 ; accepted July 20, 1951)

Extract from the fruit of the plant, Ammi Visnaga Lam, has long been employed by inhabitants of the Middle East for relief of renal colic. The major biologically active component, khellin, was isolated in impure form by Fantl and Salem in 1930 (1). The chemical structure of khellin (visammin) was established by Spath and Gruber (2), and the pharmacology of this compound was investigated by several groups in Egypt, chief among them being Samaan (3) and Anrep, Barsoum, and Kenawy (4). These investigators have reported that khellin exhibits marked coronary dilator, bronchodilator and antispasmodic activity.

Reports of beneficial results from its use in angina pectoris $(5,6)$ and in bronchial asthma $(7)$ prompted the Cardiovascular Department of this institution to investigate the effect of khellin in these diseases and in chronic cor pulmonale. The results of these studies have been previously reported elsewhere (8). In that study eight patients, clinically judged to have chronic cor pulmonale, were included. This group was characterized by pulmonary disease, diminished vital capacity, and in some instances, clubbing of the fingers and cyanosis. Four of the patients were in congestive heart failure. In all eight patients, khellin therapy resulted in improvement characterized by amelioration of dyspnea and wheezing, decreased cyanosis, increase in exercise capacity and an increased sense of well being.

In order to delineate the mechanism responsible for the improvement noted in these patients, and to apply objective physiological criteria to such

\footnotetext{
1 Aided in part by a grant from the National Heart Institute ( $H$ 218) and a grant from Smith, Kline and French Laboratories.

2 Khellin was supplied in the form of Eskel by Smith, Kline and French Laboratories.

8 Postdoctorate Research Fellow, National Heart Institute.

4 These departments are aided in part by the Michael Reese Research Foundation.
}

studies, the present cardio-pulmonary investigation was undertaken.

\section{METHOD}

The patients in the present study consisted of six males with chronic pulmonary disease, not all of whom were as ill as those in the previous study (8). The patients were out-patients selected from the Mandel Clinic. Physical examination, fluoroscopy, chest films and electrocardiograms were taken shortly before the study. The electrocardiogram was normal in one patient and abnormal in five, but none showed evidence of right heart strain. The hemoglobin content of the blood ranged from 13.7 to $20.8 \mathrm{gm} . \%$; the hematocrits, from 48 to 59 . The clinical data are summarized in Table I. All therapy was stopped for four to seven days before the study.

The general plan of the study was to determine the effect of khellin on certain aspects of the respiratory and circulatory dynamics. The technique of right heart catheterization was combined with the simultaneous determination of respiratory gases in the arterial blood and in expired air, at rest and during exercise. Studies were made immediately before and after an intramuscular dose of the drug and were repeated after five to eight days of daily oral administration.

Preliminary respiratory studies, consisting of maximum breathing capacity, vital capacity, inspiratory capacity and expiratory reserve volume (9) were determined at the beginning of the study. For this purpose a 9 liter Benedict-Roth spirometer was used. It was fitted with a vitalometer and the flutter valves and the soda lime chamber were removed (10). On the day of catheterization, the patient came to the cardio-pulmonary laboratory in the post-absorptive state. The cardiac catheter was introduced into the pulmonary artery or one of its main branches according to the technique of Cournand and Ranges (11). An indwelling needle was inserted into the brachial artery for the duration of the procedure.

Expired air was collected using an open circuit technique. A face mask was connected through a Robinson type, high-velocity valve to three Douglas bags and a Tissot spirometer in series. After an initial period of recumbency of at least 20 minutes, a five minute resting sample of expired air was collected, and, half way through this period, simultaneous brachial artery and pulmonary artery blood samples were obtained for the determination of resting cardiac output. Resting pulmonary and brachial arterial pressures were recorded by means of a capacitance 


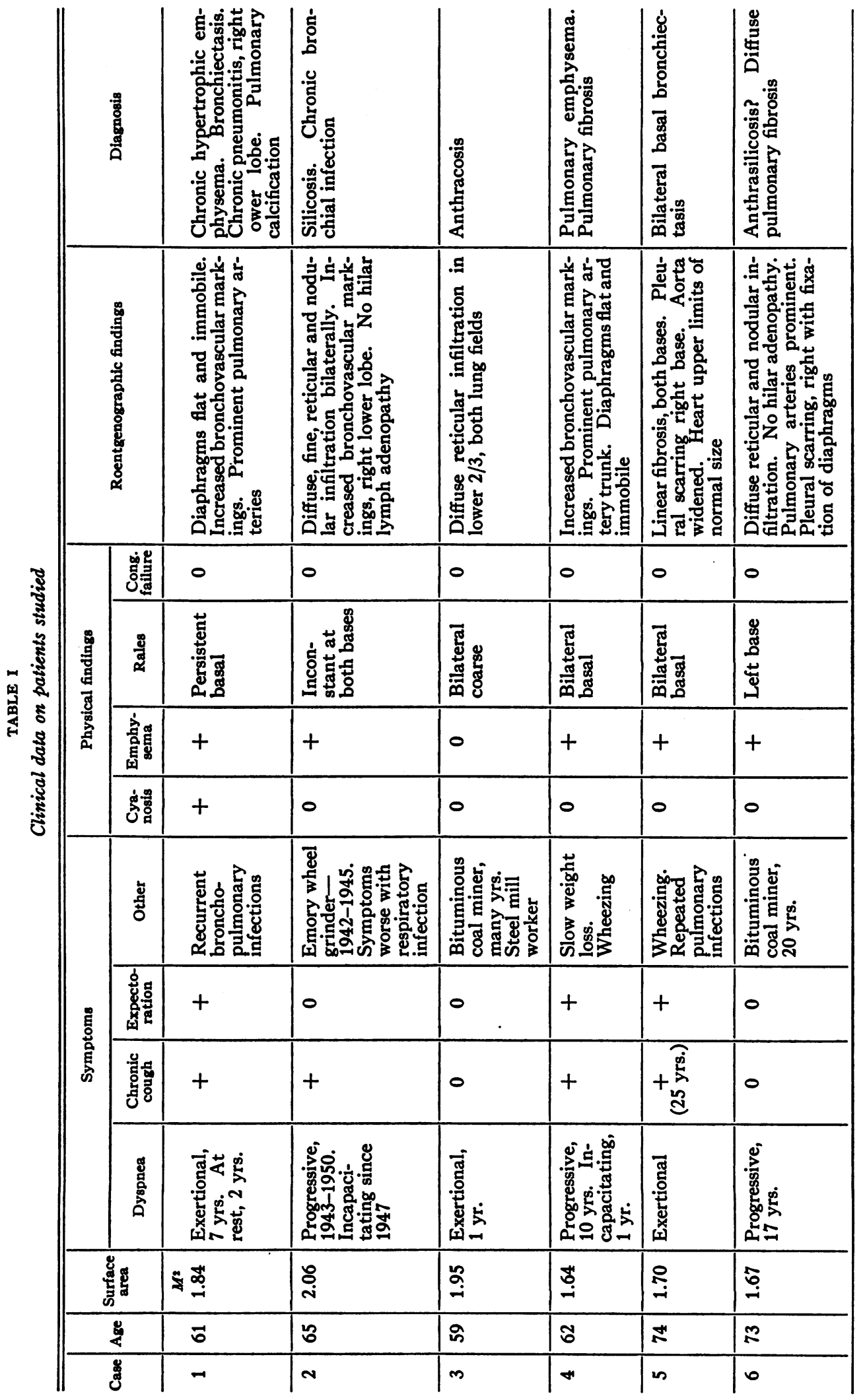


electromanometer and direct writing multi-channel oscillograph. ${ }^{5}$ The patients then exercised in the recumbent position, using a bicycle fitted with a brake and attached to the end of the fluoroscopic table. The exercise period was three minutes except in case 2 where dyspnea supervened at $2 \frac{1}{2}$ minutes, and in case 6 where the patient developed pain in the right hip after two minutes. The exercise was only roughly standardized. The expired air was collected separately in three Douglas bags for (1) the first minute of exercise, (2) the remainder of the exercise period, and (3) the first minute of recovery. The expired air from the beginning of the second minute of recovery through the fifth minute of recovery was collected in the Tissot spirometer. The volumes of gas in the Douglas bags and the Tissot were determined, and samples were taken for analysis.

After a rest period of 20 minutes, the resting determinations were repeated and the patient was given $300 \mathrm{mg}$. of khellin intramuscularly. Twenty minutes later the resting and exercise determinations were again carried out. After completion of these studies the patient was maintained in the hospital on unrestricted activity and was given $200 \mathrm{mg}$. of khellin orally for four to seven days. Except for penicillin given for two days after catheterization, as prophylaxis against infection, the patient received no other medication. At the end of this period of time, the cardio-pulmonary studies were repeated at rest and during exercise. The maximum breathing capacity, vital capacity and its compartments were repeated after the second catheterization.

Blood gas analysis was carried out according to the technique of Van Slyke and Neill (12). The expired air samples were analyzed for oxygen by a Pauling oxygen analyzer, and for carbon dioxide by the Haldane technique. The average minute ventilation for the various periods was calculated and expressed as liters per minute at $37^{\circ} \mathrm{C}$. ambient pressure and saturated with water vapor (B.T.P.S.). The oxygen removal in cc. per liter of ventilation, the average oxygen uptake in cc. per minute (10), and the oxygen debt for the entire five minutes of recovery were also calculated. The oxygen debt was calculated as follows: pressure as well. All of the patients demonstrated a resting oxygen uptake which was within normal limits, except case 5 in which the oxygen uptake was elevated at rest initially, but fell to a normal level 25 minutes after exercise. The ventilation at rest was elevated in all patients except case 4 . The oxygen removal was decreased in all cases. Thus all patients demonstrated some degree of hyperventilation at rest (Table II).

The response to exercise was normal in all cases with respect to cardiac index and arteriovenous oxygen difference (13). The cardiac indices ranged from 3.4 to $5.1 \mathrm{~L} / \mathrm{min}$. $/ \mathrm{M}^{2} \mathrm{~B} . \mathrm{S}$. representing $140-250 \%$ of the resting values. The arterio-venous oxygen differences ranged between 6.7 to 8.2 vol.\% representing $127-187 \%$ of the resting values. During exercise, the oxygen uptake rose to between two and $31 / 3$ times the resting level (Table II). Hyperventilation persisted during exercise, but there was a rise in the oxygen removal above the resting level. This change was demonstrated in all cases. The oxygen debt for the first five minutes of recovery ranged between $13 \%$ and $22 \%$ in the four cases in which this information was available. Exercise produced a rise in systolic and diastolic pulmonary arterial pressure in five cases. In one case, there was elevation only of the systolic pressure. The greatest increment of pressure rise occurred during systole, ranging from 10 to $30 \mathrm{~mm}$. $\mathrm{Hg}$. The diastolic pressure rise varied from 4 to $10 \mathrm{~mm}$. $\mathrm{Hg}$. In two cases (cases 5 and 6 ) pulmonary artery and right ventricular pressures were recorded simultaneously. In case 6 , the diastolic pressure in the right ventricle rose to abnormal levels during exercise,

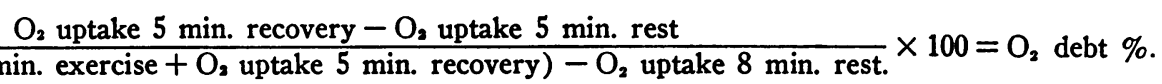
Cardiac output was determined by the direct Fick principle.

\section{RESULTS}

On initial study the resting arterio-venous oxygen difference and cardiac index were within normal limits in all cases. The cardiac indices ranged from 2.0 to $3.7 \mathrm{~L} / \mathrm{min}$. $/ \mathrm{M}^{2} \mathrm{~B}$.S.; the $\mathrm{A}-\mathrm{V}$ differences, from 4.1 to 5.9 vol.\%. The pulmonary arterial pressure was elevated in two cases, one of which (case 1) had an elevation of the diastolic

- Sanborn polyviso. indicating acute right heart failure (Table II).

Twenty-five minutes after the completion of exercise, and just prior to the injection of khellin, the cardiac index was at or below the previous resting level in three cases. In the remaining cases, the cardiac index remained above the original resting level. The arterio-venous difference was essentially unchanged in five cases. In one case, the arterio-venous difference was below resting level. The oxygen uptake deviated from the initial determination by $20 \mathrm{cc} / / \mathrm{min} . / \mathrm{M}^{2} \mathrm{~B}$.S. or less in four cases. In one case the oxygen uptake was 


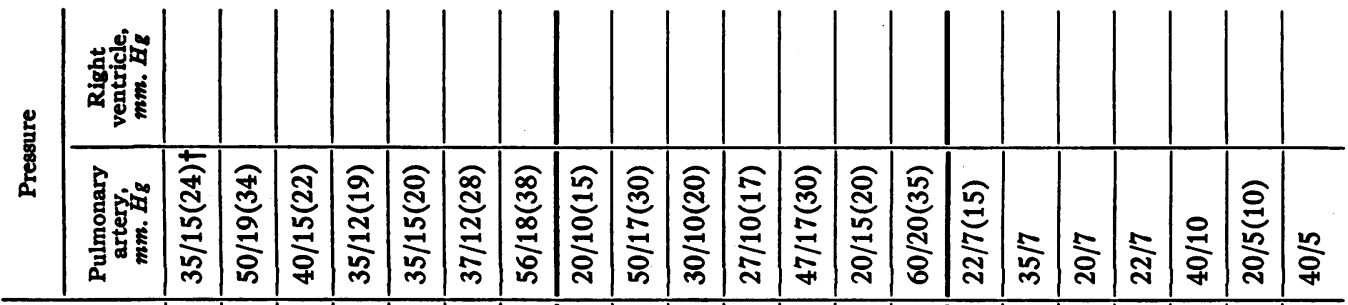

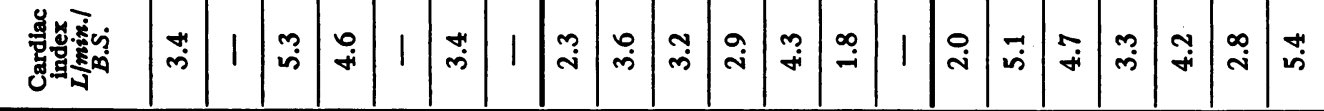

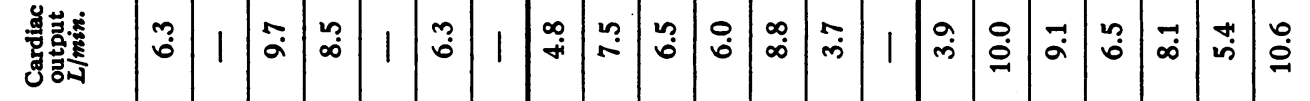



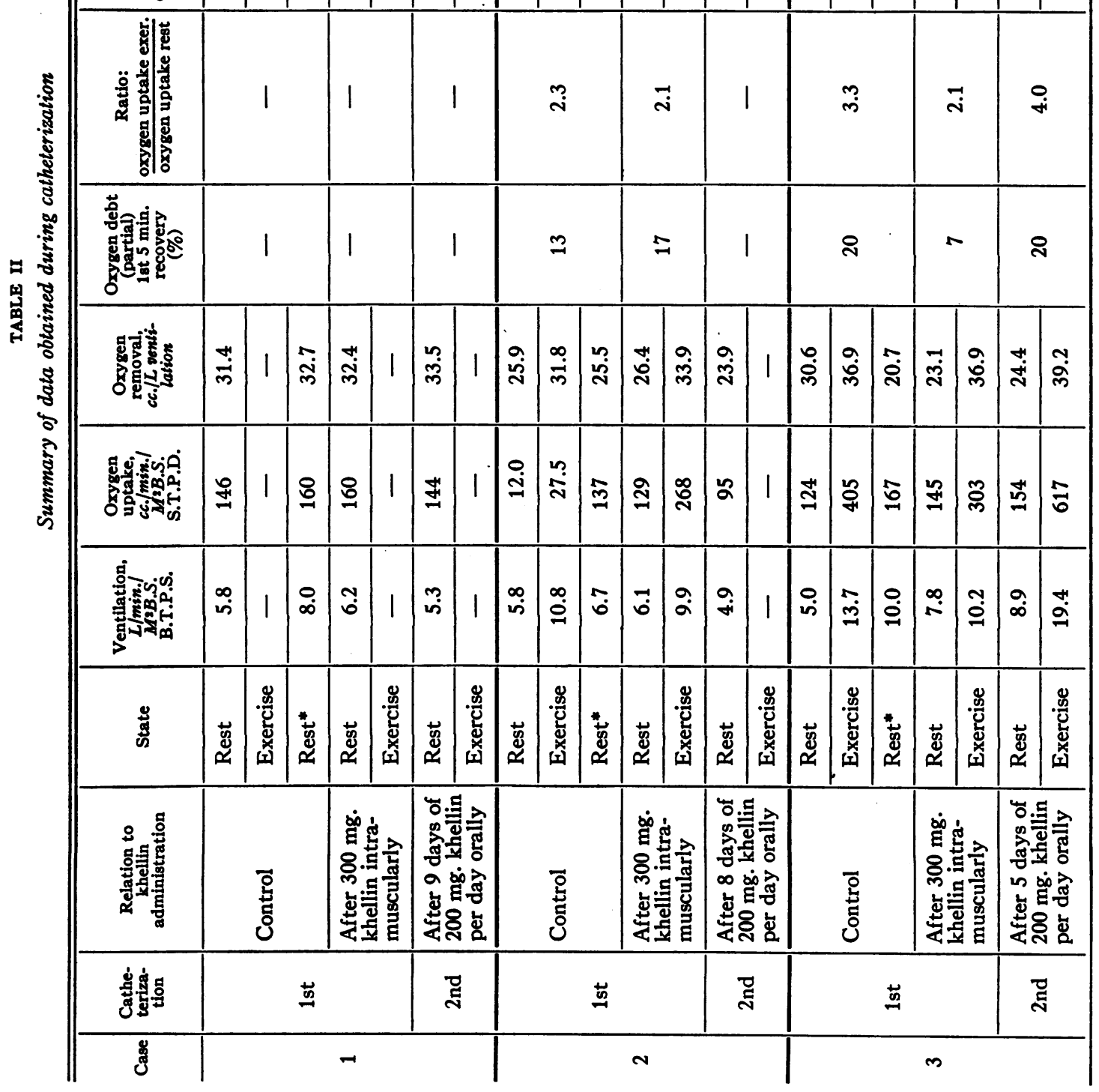




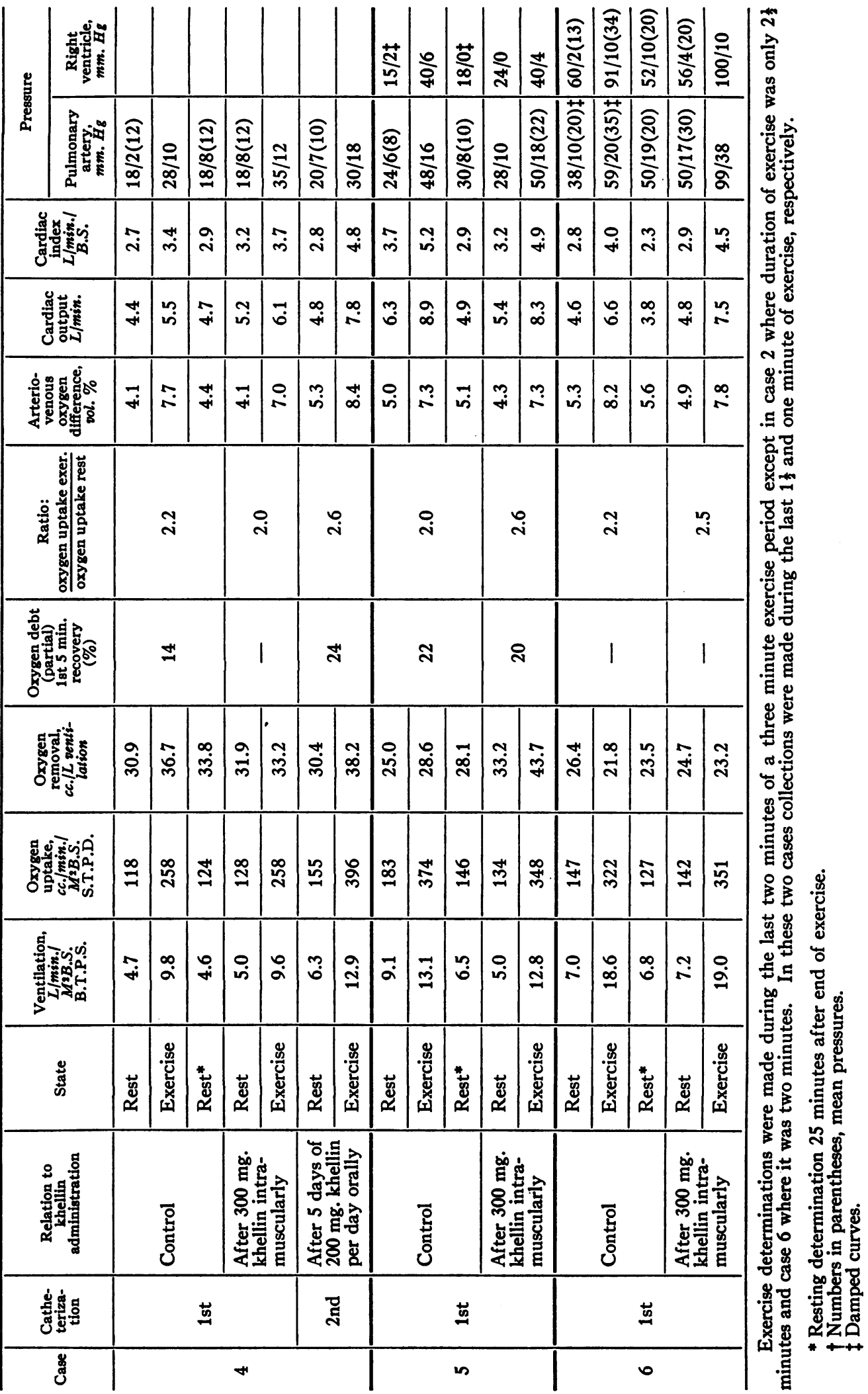


significantly higher and in another was significantly lower than the initial determination. In general, ventilation showed similar changes. In four cases the pulmonary artery pressure returned to the original resting levels. In one case, the systolic pressure remained elevated (case 2 ). In one case, the character of the pulmonary artery curves did not permit adequate comparison. However, comparison of ventricular pressure curves during the resting states shows systolic levels of the same order of magnitude (Table II).

The arterial blood oxygen saturation was within normal limits at rest in three cases, but was below $95 \%$ in cases 4 and 6 . With exercise, there was a fall in the arterial oxygen saturation in the four cases in which this was measured. Only in case 3 did the arterial oxygen saturation, during exer- tained 25 minutes following exercise. In case 3 the oxygen uptake was considerably higher and in case 5 was considerably lower than the original determination. During exercise these values were remarkably similar to those obtained during the control period except in case 3 where the oxygen uptake was lower and case 5 where the oxygen removal was higher. Five of the six cases showed a rise in the pulmonary artery pressure to the same degree as before khellin administration. One case (case 1) showed no change in pulmonary artery pressure (Table II).

A second catheterization was performed in four cases following several days of administration of oral khellin. At rest the arterio-venous oxygen difference, cardiac index and pulmonary arterial pressures were unchanged from the resting level

TABLE III

Summary of blood gas data

\begin{tabular}{|c|c|c|c|c|c|c|c|c|c|}
\hline \multirow[b]{2}{*}{ Arterial blood gases } & \multirow{2}{*}{$\begin{array}{c}\text { Case } 1 \\
\begin{array}{l}\text { Before } \\
\text { khellin }\end{array}\end{array}$} & \multicolumn{2}{|c|}{ Case 2} & \multicolumn{2}{|c|}{ Case 3} & \multicolumn{2}{|c|}{ Case 4} & \multirow{2}{*}{$\begin{array}{c}\text { Case } 5 \\
\begin{array}{c}\text { Before } \\
\text { khellin }\end{array}\end{array}$} & \multirow{2}{*}{ Case 6} \\
\hline & & $\begin{array}{l}\text { Before } \\
\text { khellin }\end{array}$ & $\begin{array}{l}\text { After } 8 \\
\text { days of } \\
\text { khellin }\end{array}$ & $\begin{array}{l}\text { Before } \\
\text { khellin }\end{array}$ & $\begin{array}{l}\text { After } 5 \\
\text { days of } \\
\text { khellin }\end{array}$ & $\begin{array}{l}\text { Before } \\
\text { khellin }\end{array}$ & $\begin{array}{l}\text { After } 7 \\
\text { days of } \\
\text { khellin }\end{array}$ & & \\
\hline $\begin{array}{l}\text { Oxygen Saturation, \% } \\
\text { Resting } \\
\text { Exercise }\end{array}$ & $\frac{80.5}{-}$ & $95.5^{\prime}$ & $\begin{array}{l}94.5 \\
91.5\end{array}$ & $\begin{array}{r}100 \\
93\end{array}$ & $\begin{array}{l}95 \\
88.6\end{array}$ & $\begin{array}{l}86.6 \\
77.0\end{array}$ & $\begin{array}{l}88.2 \\
81.0\end{array}$ & $\begin{array}{r}97.2 \\
866.2\end{array}$ & $\begin{array}{l}87.2 \\
79.7\end{array}$ \\
\hline $\begin{array}{l}\mathrm{CO}_{2} \text { Saturation, } \% \\
\text { Resting } \\
\text { Exercise }\end{array}$ & 二 & $\begin{array}{l}45.1 \\
42.9\end{array}$ & $\underline{45.8}$ & $\begin{array}{l}38.8 \\
41.0\end{array}$ & $\begin{array}{l}39.9 \\
41.9\end{array}$ & $\begin{array}{l}53.3 \\
56.4\end{array}$ & $\begin{array}{l}50.9 \\
53.4\end{array}$ & $\begin{array}{l}42.4 \\
41.0\end{array}$ & $\begin{array}{l}44.3 \\
43.2\end{array}$ \\
\hline
\end{tabular}

cise, remain within normal limits. The resting carbon dioxide contents were below normal limits in all except case 4 . The response to exercise consisted of a slight rise in the $\mathrm{CO}_{2}$ content in two cases and a slight fall in three (Table III).

Twenty minutes after the injection of $300 \mathrm{mg}$. khellin, there was no significant change from the resting values of the arterio-venous oxygen difference, cardiac index, and pulmonary arterial pressure (Table II). In four of the five cases for which such data are available, the changes in arterio-venous oxygen difference and cardiac index rose to the same extent with exercise as was observed prior to administration of the drug. In one case (case 3 ) the cardiac index rose less with exercise than before khellin. The resting oxygen uptake, ventilation and oxygen removal showed no consistent deviation from the resting data ob- obtained during the control period of the first catheterization. During exercise the increase in arterio-venous oxygen difference was of the same order of magnitude as that observed with exercise during the control period of the first catheterization in three cases, while in one case (case 3 ) it was significantly increased. The cardiac index in the two cases in which cardiac output was measured was increased to the same extent as during the control period of exercise. No significant changes in oxygen uptake, ventilation or oxygen removel were noted during rest or exercise. In case 3 , the severity of exercise was greater than during the control period but there was no significant increase in oxygen removal. The oxygen debt data are incomplete, and the changes noted are probably not significant. Bruce and his associates (14) and Baldwin, Cournand, and Richards (10) 
TABLE IV

Summary of respiratory data

\begin{tabular}{|c|c|c|c|c|c|c|c|c|c|}
\hline \multirow{2}{*}{ Case } & \multirow{2}{*}{ Time } & \multicolumn{2}{|c|}{$\begin{array}{l}\text { Maximal breathing } \\
\text { capacity in liters }\end{array}$} & \multicolumn{2}{|c|}{$\begin{array}{l}\text { Vital capacity } \\
\text { in cc. }\end{array}$} & \multicolumn{2}{|c|}{$\begin{array}{l}\text { Inspiratory capacity } \\
\text { in cc. }\end{array}$} & \multicolumn{2}{|c|}{$\begin{array}{l}\text { Expiratory reserve } \\
\text { volume in cc. }\end{array}$} \\
\hline & & Determined & Predicted & Determined & Predicted & Determined & Predicted & Determined & Predicted \\
\hline \multirow[t]{2}{*}{2} & \multirow{2}{*}{$\begin{array}{l}\text { Pre-khellin } \\
\text { After } 5 \text { days on } \\
\text { khellin }\end{array}$} & 81 & 110 & 2,730 & 3,560 & 800 & 640 & 1,900 & 2,920 \\
\hline & & 102 & - & 3,300 & - & 1,440 & 一 & 1,900 & - \\
\hline \multirow[t]{2}{*}{3} & \multirow{2}{*}{$\begin{array}{l}\text { Pre-khellin } \\
\text { After } 5 \text { days on } \\
\text { khellin }\end{array}$} & 97 & 109 & 2,990 & 3,510 & 500 & 630 & 2,200 & 2,910 \\
\hline & & 110 & 一 & 3,030 & - & 900 & - & 2,260 & - \\
\hline \multirow[t]{2}{*}{4} & \multirow{2}{*}{$\begin{array}{l}\text { Pre-khellin } \\
\text { After } 6 \text { days on } \\
\text { khellin }\end{array}$} & 25 & 89 & 2,270 & 3,460 & 660 & 600 & 1,720 & 2,860 \\
\hline & & 31 & - & 3,070 & 一 & 1,270 & 一 & 2,220 & 一 \\
\hline \multirow[t]{2}{*}{5} & \multirow{2}{*}{$\begin{array}{l}\text { Pre-khellin } \\
\text { After } 8 \text { days on } \\
\text { khellin }\end{array}$} & 52 & 82 & 2,550 & 2,990 & 860 & 520 & 1,740 & 2,470 \\
\hline & & 72 & - & 2,300 & 一 & 910 & 一 & 1,560 & 一 \\
\hline 6 & Pre-khellin & 65 & 81 & 2,280 & 3,340 & 950 & 580 & 1,590 & 2,760 \\
\hline
\end{tabular}

have pointed out the great variability of this determination. The response of the pulmonary arterial pressure to exercise in all four cases was similar quantitatively to that observed prior to administration of the drug (Table II).

All of the spirographic tracings showed trapping of air. The maximum breathing capacities were reduced in all cases, ranging from $36 \%$ to $89 \%$ of the predicted values. The vital capacities were also reduced but to a lesser degree than that of the maximum breathing capacities (Table IV). The spirographic tracings showed slowing of expiration in all cases, marked in cases 2,4 and 5 . The maximum breathing capacity was performed in an extreme inspiratory position in all instances, except case 3. This patient performed the test in the midposition and showed the least reduction from the predicted value. In four patients spirometry was repeated after a number of days of administration of $200 \mathrm{mg}$. of khellin daily. These patients displayed a slight to moderate increase in the maximum breathing capacity; the mean increase was $15 \mathrm{~L} / \mathrm{min}$., representing changes of $24 \%, 27 \%$, $39 \%$ and $14 \%$ from the control level. The vital capacity was significantly increased in two cases with no significant change in the others. The expiratory reserve volume was increased in one case, decreased in one case and unchanged in two.

There were no objective or subjective clinical signs of improvement noted after the intramuscular injection of khellin.
At some time during the course of oral khellin administration, all of the patients volunteered the information that it was "easier to get air in and out of the chest." There was no objective improvement in the cyanosis, dyspnea, exercise capacity, or physical findings.

\section{DISCUSSION}

The six patients comprising this study were selected on the basis of extensive chronic pulmonary disease and clinical disability which led to the suspicion of chronic cor pulmonale. Neither roentgenographic evidence of right ventricular enlargement nor electrocardiographic evidence of right heart strain was present in these cases. It is well known, however, that chronic cor pulmonale may exist in the absence of these findings. The unreliability of these diagnostic aids and of the clinical symptomatology has made the diagnosis of chronic cor pulmonale uncertain in the absence of right heart failure or a previous history of such an episode. This has been previously pointed out by Ferrer and his associates (15).

Only two of the six cases displayed pulmonary hypertension at rest; the remaining four developed pulmonary hypertension during exercise. In one of the patients with resting hypertension, pressures were recorded from the right ventricle and exhibited elevation of the end diastolic pressure in this chamber to early failure levels during exercise. Thus, it can be seen that only one of our patients 
may be considered to have proven cor pulmonale, the remaining five are examples of pulmonary hypertensive heart disease without proven cor pulmonale. ${ }^{\circ}$

The cardiac output at rest and with exercise was normal in this group of patients. Impaired respiratory function, varying from mild to severe, was demonstrated by the maximum breathing capacity and vital capacity. In addition, hypoxemia was present to some degree in three of the six cases and developed in the other three during exercise. All of the patients demonstrated hyperventilation both at rest and during exercise, but showed a rise in oxygen removal during exercise. Since the oxygen uptake was within normal limits the hyperventilation may be considered compensatory.

Khellin administered intramuscularly produced no significant changes in the cardiac output. There was no alteration of the pulmonary arterial pressure at rest, nor was there any demonstrable protective action in preventing a rise in the pulmonary arterial pressure with exercise. In this regard, in case 1 , exercise after khellin was accompanied by no rise in pulmonary arterial pressure. However, during the second catheterization following intramuscular khellin, the pulmonary pressure rose in the same manner observed in all other patients. Since measurements of cardiac output during exercise were not obtained in this case and the exercise was not precisely quantitated, the failure of the pulmonary artery pressure to rise at the time of the first catheterization cannot be accurately appraised. The occurrence of pulmonary hypertension with exercise during the second catheterization would suggest the first observation in this case has no significance.

Intramuscular khellin produced no consistent changes in ventilation, oxygen uptake and oxygen removal. The changes which occurred were probably within the limits of the experimental error.

Prolonged administration of khellin did not alter the hemodynamic pattern observed before its administration. Cardiac output and pulmonary pressure at rest and their responses to exercise were essentially unchanged. However, there was an increase in maximum breathing capacity in the four cases in which this information was available.

- Pulmonary hypertensive heart disease is the subject of a forthcoming publication.
No constant changes were found in ventilation, oxygen uptake, oxygen removal or oxygen debt. Khellin did not appear to have any "protective" effect on the arterial saturation during exercise.

Correlation of the subjective clinical improvement with the increase in maximum breathing capacity without any change in the other cardiorespiratory functions studied, suggests that khellin had a bronchodilator effect in these four cases. All of the patients were judged to be clinically free of active bronchopulmonary infection at the time of study and for this reason it was felt that the effect of brief administration of penicillin on the aspects of pulmonary function measured could be disregarded. Nevertheless, the possibility that the observed increase in maximum breathing capacity was, at least in part, on this basis cannot be excluded. Study of a larger series of cases is necessary to properly evaluate the significance of this observation. The increase in maximum breathing capacity was not accompanied by any diminution of pulmonary arterial pressure; the effect of more potent bronchodilators deserves investigation in this regard.

It is apparent that there is a striking disparity in the results previously reported by Rosenman and his associates (8) and the results obtained in this study. This discrepancy may be due in part to the apparently greater severity of disability of the patients in the earlier study and in part to the well known difficulty in accurately evaluating improvement to any method of therapy by non-objective criteria.

\section{SUMMARY}

1. Six patients with chronic pulmonary disease were studied with respect to the effect of khellin on certain aspects of cardio-pulmonary function.

2. Khellin given intramuscularly produced no consistent change during rest or exercise in ventilation, oxygen uptake, oxygen removal, cardiac output or pulmonary arterial pressure. The changes which did occur were probably within the limits of the experimental error.

3. Restudy after a course of oral khellin, revealed an increase in maximum breathing capacity in the four cases in which this information was available. No consistent changes were found in ventilation, oxygen uptake, oxygen removal, 
cardiac output or pulmonary arterial pressure. Khellin did not appear to have any "protective" effect on the arterial saturation during exercise.

\section{ACKNOWLEDGMENTS}

We are indebted to Mrs. A. Lieffers, Miss J. Cooper, and $\mathrm{Mr}$. W. Brotherton and to the members of the catheterization team for their valuable assistance in carrying out these studies.

\section{REFERENCES}

1. Fantl, P., and Salem, S. I., Chellol Glucosid. Biochem. Ztschr., 1930, 226, 166.

2. Smith, Kline \& French Laboratories, Personal communication.

3. Samaan, K., The pharmacological action of the glucoside khellin. Quart. J. Pharm. \& Pharmacol., 1932, 5, 6 and 183.

4. Anrep, G. V., Barsoum, G. S., and Kenawy, M. R., The pharmacological actions of the crystalline principles of Ammi Visnaga Lam. J. Pharm.\& Pharmacol., 1949, 1, 164.

5. Kenawy, M. R., and Barsoum, G. S., Ammi Visnaga in the treatment of the anginal syndrome. Gaz. fac. med., Cairo, 1945, 13, 39.

6. Anrep, G. V., Barsoum, G. S., Kenawy, M. R., and Misrahy, G., Ammi Visnaga in the treatment of the anginal syndrome. Brit. Heart J., 1946, 8, 171.

7. Anrep, G. V., Barsoum, G. S., Kenawy, M. R., and
Misrahy, G., Therapeutic uses of khellin: method of standardization. Lancet, 1947, 1, 557.

8. Rosenman, R. H., Fishman, A. P., Kaplan, S. R., Levin, H. G., and Katz, L. N., Observations on the clinical use of visammin. J. A. M. A., 1950, 143, 160.

9. Standardization of definitions and symbols in respiratory physiology. Federation Proc., 1950, 9, 602.

10. Baldwin, E. deF., Cournand, A., and Richards, D. W., Jr., Pulmonary insufficiency; physiological classification, clinical methods of analysis, standard values in normal subjects. Medicine, 1948, 27, 243.

11. Cournand, A., and Ranges, H. A., Catheterization of the right auricle in man. Proc. Soc. Exper. Biol. \& Med., 1941, 46, 462.

12. Peters, J. P., and Van Slyke, D. D., Quantitative Clinical Chemistry. Vol. II, Methods. Williams \& Wilkins, Baltimore, 1932, Chap. VII, p. 267.

13. Hickam, J. B., and Cargill, W. M., Effect of exercise on cardiac output and pulmonary arterial pressure in normal persons and in patients with cardiovascular diseases and pulmonary emphysema. J. Clin. Invest., 1948, 27, 10.

14. Bruce, R. A., Pearson, R., Lovejoy, F. W., Jr., Yu, P. G., and Brothers, G. B., Variability of respiratory and circulatory performance during standardized exercise. J. Clin. Invest., 1949, 28, 1431.

15. Ferrer, M. I., Harvey, R. M., Cathcart, R. T., Webster, C. A., Richards, D. W., Jr., and Cournand, A., Some effects of digoxin upon the heart and circulation in man. Digoxin in chronic cor pulmonale. Circulation, 1, 1950, 161. 